
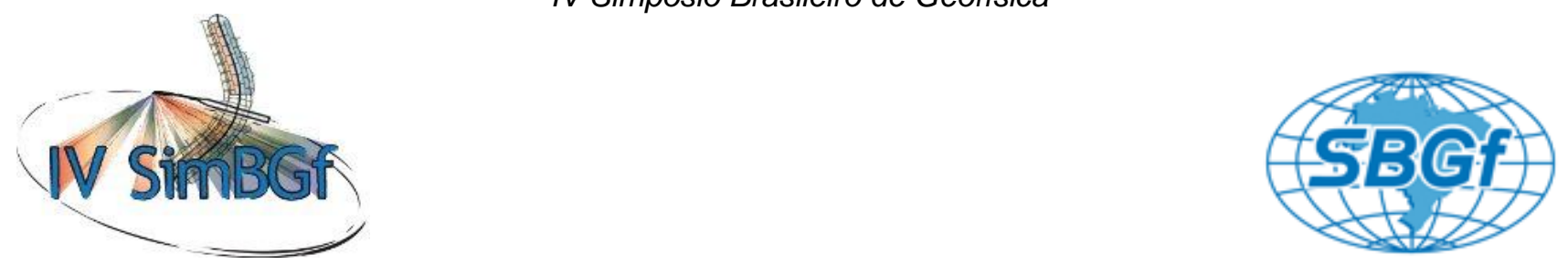

\title{
Prospecção de fosforitos utilizando gamaespectrometria terrestre.
}

Chris Busnello Fianco, Roberta Mary Vidotti e Augusto C. B. Pires

UnB / IG-LGA

\section{Copyright 2008, SBGf - Sociedade Brasileira de Geofísica}

Este texto foi preparado para a apresentação no IV Simpósio Brasileiro de Geofísica, Belém, 14 a 17 de novembro de 2010. Seu conteúdo foi revisado pelo Comitê Técnico do IV SimBGf, mas não necessariamente representa a opinião da SBGf ou de seus associados. É proibida a reprodução total ou parcial deste material para propósitos comerciais sem prévia autorização da SBGf.

\section{Resumo}

O Grupo Bambuí, onde está localizada a área de trabalho, possui em seu desenvolvimento um ambiente favorável à formação de rochas fosfáticas, apresentandose assim como uma área de interesse econômico. A utilização do método gamaespectrométrico tem como finalidade a seleção de alvos para prospecção de minério, uma vez que a apatita, mineral fosfático, geralmente apresenta um teor elevado de U. Para este fim foi realizada a aquisição de, aproximadamente, $10 \mathrm{~km}$ lineares, totalizando 527 estações de dados gamaespectrometricos terrestres ao longo de cinco perfis. A análise dos dados dos radioelementos obtidos e suas razões indicam que o enriquecimento de $U$ em relação ao K, é bem mapeado pelas razões UTh e UK, o que foi confirmado em cheque de campo.

\section{Introdução}

Localizada no nordeste do Estado de Goiás e sudeste do Tocantins, a área de estudo encontra-se a cerca de 330 $\mathrm{km}$ de Brasília. Com uma extensão de aproximadamente $7.000 \mathrm{~km}^{2}$, a área alongada na direção N-S abrange municípios como Campos Belos, Monte Alegre de Goiás e Nova Roma em Goiás e Arraias no Tocantins.

A sedimentação do Grupo Bambuí, na Faixa Brasília, teve início com os diamictitos durante um período glacial. $O$ derretimento das camadas de gelo permitiu a instalação de um ambiente marinho epicontinental, e iniciou-se a deposição de sedimentos pelitocarbonatados que se sobrepõe ao Cráton São Francisco (figura 1). O ambiente criado em função da deglaciação estabeleceu também as condições climáticas necessárias para a deposição dos sedimentos fosfáticos na região (Dardenne, 1978).

A geologia utilizada no trabalho (Figura 1) é resultado do levantamento geológico das folhas Monte Alegre de Goiás, Nova Roma e Cavalcante, em escala 1:100.000, realizado pelo programa Geologia do Brasil (PGB/PGL) do Serviço Geológico do Brasil (CPRM) em 2006 (Monteiro, 2009). Uma característica marcante que pode ser observada na área é a diferenciação de rochas de origem ígnea (embasamento) na porção oeste, e de rochas de origem sedimentar na porção leste da área.

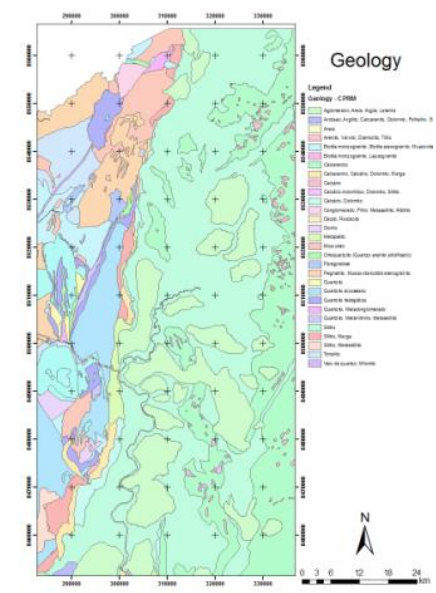

Figura 1 - Mapa da geologia da área de estudos (Monteiro, 2009).

$\mathrm{Na}$ área de estudos a cobertura vegetal é pouco densa, podendo esta ser percorrida sem maiores dificuldades; o clima semiárido é responsável pela existência de um manto de alteração pouco espesso e descontínuo, que favorece a ocorrência de afloramentos rochosos. Ferreira et al. (1992) relataram que rochas calcárias geralmente apresentam baixos teores de elementos radioativos. Isto permitiria um contraste das rochas mineralizadas na região, uma vez que a apatita geralmente possui um teor elevado de $U$ e Th e, a rocha encaixante normlmente é o calcário.

Durante o período de 04 a 21 de maio de 2010 foi realizado o trabalho de campo, com aquisição de dados de geofísica terrestre, utilizando o método gamaespectrométrico, onde foram medidos os teores médios dos elementos $\mathrm{K}$, Th, U e contagem total.

O levantamento foi realizado em perfis pré-selecionados com base nos resultados obtidos para mapeamento das áreas anômalas de urânio e flúor (Figura 1), levando em consideração o resultado do processamento de dados de geofísica aérea (Fianco et al., 2010), geoquímica de sedimento de corrente e também a geologia conhecida para a região, ambos disponíveis no SIG de Goiás (Moreira et al., 2008).

Os cinco perfis (Figura 2) selecionados e executados obedeceram a diferentes padrões de escolha, sendo o primeiro deles traçado em função das anomalias de urânio, flúor e fósforo mapeados, apesar de existir apenas uma litologia mapeada; o segundo, assim como no primeiro caso, apresentou feições anômalas de urânio, flúor e fósforo, porém apresentando diferentes 
litologias ao longo do perfil; o terceiro perfil, de acordo com mapeamento geológico realizado pela empresa Itafós Mineração, apresenta como litologia apenas siltito, contudo apresenta anomalias nos mapas de urânio e flúor estimado; o quarto perfil traçado sobre siltito foi selecionado com base na assinatura anômala de flúor e fósforo, não apresentando nenhuma feição anômala em urânio; o quinto perfil foi executado em uma área próxima a mina (no estado do Tocantins), sobre siltito e fosforito mapeado pela Itafós, em uma linha onde já existiam informações de geoquímica, esta última região não é recoberta pelos dados aerogeofísicos utilizados para gerar o mapa apresentado na figura 2.

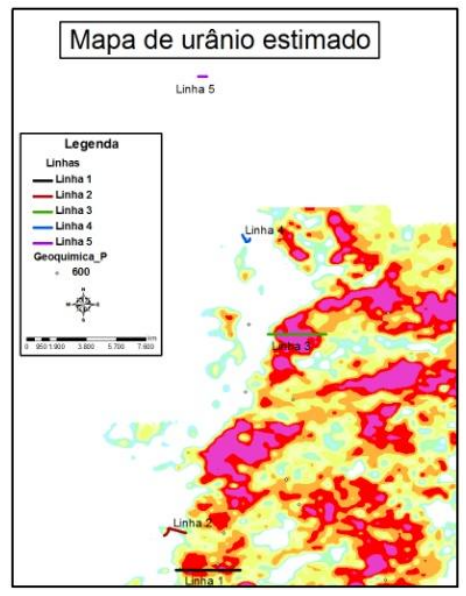

Figura 2 - Mapa de urânio estimado com os pontos de amostragem geoquímica com valores acima de 600 ppm e localização dos 5 perfis de gamaespectrometria terrestre.

\section{Aquisição de dados}

O gamaespectrômetro utilizado durante o levantamento foi o modelo GR-320,com um detector de iodeto de sódio ativado com tálio ( $\mathrm{Nal}(\mathrm{TI})$ ) com dimensões de $75 \mathrm{~mm}$ de diâmetro por $75 \mathrm{~mm}$ de espessura. A resolução é de 256 canais, e apresenta uma fonte interna de césio na base do detector para estabilização do sistema (Exploranium, 2007).

Foram executados no total aproximadamente 10.712 metros de levantamento, com estações de amostragem a cada 20 metros de espaçamento, totalizando 527 estações no total (Tabela 1). Em cada estação o tempo de leitura pelo espectrômetro foi de 300 segundos, este tempo de leitura tem como base a recomendação do guia de mapeamento radiométrico (IAEA, 2003).

Tabela 1 - A tabela abaixo mostra a extensão de cada um dos perfis, bem como o número de estações executadas em cada um deles.

\begin{tabular}{|l|c|c|}
\hline Perfil / Bloco & Total (m) & Numero de estações \\
\hline Perfil 1 / Leste & 3.885 & 197 \\
\hline Perfil 2 / Lucia & 1.688 & 82 \\
\hline Perfil 3 / Cabeçudo & 3.709 & 179 \\
\hline Perfil 4 / Avião & 850 & 41 \\
\hline Perfil 5 / Coité & 580 & 28 \\
\hline Total & 10.712 & 527 \\
\hline
\end{tabular}

Conforme informações verbais fornecidas pelos geólogos da Mineração Itafós, os corpos mineralizados na região apresentam, em geral, extensões de até 100 metros e largura de 40 metros. Para garantir que tenhamos ao menos 1 ponto de amostragem sobre a mineralização, o espaçamento entre as estações foi definido com 20 metros, garantindo também uma boa distribuição espacial dos dados.

\section{Análise dos dados}

Os resultados da geofísica terrestre são apresentados nas Figuras, 3, 4, 5, 6 e 7. Estas apresentam os perfis dos radioelementos $U$ e Th em ppm e $K$ em porcentagem, da contagem total em cps e as razões $U / K$ e U/Th. As razões foram calculadas após analisar-se a correlação entre os perfis de cada elemento, onde observou-se uma correlação inversa entre os dados de potássio e urânio.

\section{Perfil 1}

Localizado no Bloco Leste, o perfil 1 possui 3.885 metros de extensão e direção E-W. Este perfil foi traçado nesta área em função das anomalias de $\mathrm{U}, \mathrm{F}$ e $\mathrm{P}$ mapeados com o processamento dos dados aéreos e integração com geoquímica de sedimento de corrente. Além disso, existe um ponto de amostragem de geoquímica de sedimento de corrente próximo da área com valor de $\mathrm{P}$ superior a 600 ppm, (Moreira et al., 2008). Sob esta área existe apenas uma litologia mapeada (siltito) (figura 1), porém localmente foram encontradas concreções lateríticas. Este perfil está representado pelo perfil preto na Figura 2, localizado na porção centro sul do mapa). Ao longo de quase toda a linha a variação topográfica é pequena e a vegetação quase exclusivamente pasto. $\mathrm{Na}$ extremidade leste da linha, o perfil atravessou um pequeno córrego. Este perfil não apresenta mineralização conhecida.

A litologia predominante ao longo do perfil é siltito, ocorrendo porém no início deste, blocos de calcário e ao longo do mesmo, trechos com feições de laterização. Cabe salientar aqui a existência de um córrego (indicado pela seta azul, Figura 3a).

A Figura 3 apresenta os dados pós-processados dos radioelementos $\mathrm{U}$, Th e $\mathrm{K}$; A contagem total (cps), e; as razões U/Th e U/K.

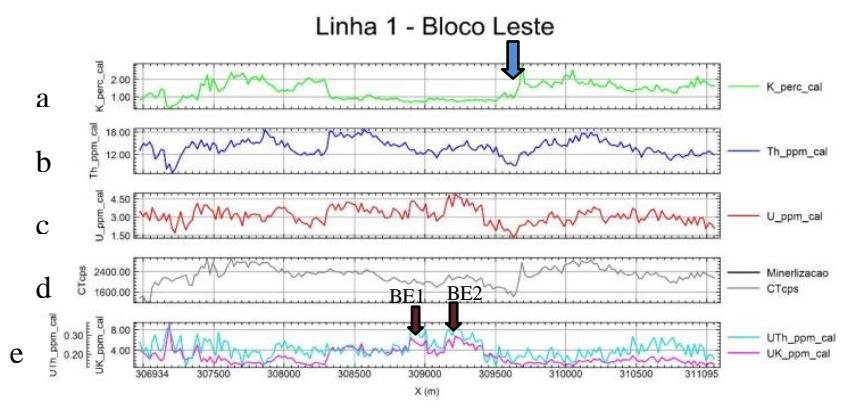

Figura 3 - Perfis dos valores dos radioelementos $\mathrm{K}(\mathrm{a})$, Th (b), $\mathrm{U}$ (c) e a contagem total (d) coletados no campo, e as razões UTh e UK (e) para o Perfil 1 do Bloco Leste. A seta azul indica a localização do córrego, e as setas marrons regiões anômalas. 
O perfil do K (Figura 3a) apresenta uma feição bastante evidente na porção central, uma região aplainada com valores em torno de $1 \mathrm{ppm}$ bordejada abruptamente por valores mais elevados do elemento. Nas outras regiões as concentrações de $\mathrm{K}$ variam entre 1 e 3 porcento, valores estes em torno do valor médio de $\mathrm{U}$ na crosta $(2,5 \%)$, sendo que no início do perfil (oeste) os valores são mais baixos.

O perfil do Th (Figura 3b) apresenta um padrão irregular, com as concentrações variando entre 8 e $18 \mathrm{ppm}$, e, de maneira geral, com valores acima do valor médio de Th na crosta (8-12 ppm). O perfil do U (Figura 3c), também apresenta um padrão irregular, com valores do radioelemento variando entre 1 e $4 \mathrm{ppm}$. Na região central, contudo, pode-se observar dois picos sutis de enriquecimento deste elemento. Nestes dois perfis podese observar melhor as regiões alagadas, uma vez que os valores dos elementos decaem significantemente.

O perfil da contagem total apresenta dois baixos significativos na concentração dos radioelementos (Figura $3 \mathrm{~d}$ ), a primeira a oeste do perfil onde existe a ocorrência de calcários e a segunda nas proximidades da coordenada leste 309500 , onde existe um córrego.

Nos perfis das razões UK e UTh (Figura 3e) é possível identificar dois picos principais, indicados pelas setas BE1 e BE2 nos quais os teores de urânio em relação ao Th e ao $K$ são elevados. Estes pontos foram selecionados para cheque de campo.

Apesar de ter sido mapeada apenas uma litologia ao longo de quase todo o perfil, a excessão do calcário no início da linha, observa-se grandes variações na concentração dos elementos ao longo do mesmo, como a região onde o K (Figura 3a) apresenta valores baixos, correlacionado a dois picos de valores de U (Figura 3C). Os dois altos assinalados no perfil das razões (BE1 e BE2) poderiam ser eventualmente explicados pela presença de concreções lateríticas encontradas nesta região.

\section{Perfil 2}

Localizado no Bloco Lúcia, o perfil 2 apresenta $1.688 \mathrm{~m}$ de extensão e foi traçado por cortar diferentes litologias, inclusive um fosforito mapeado pela Itafós. Esta área não apresenta nenhum ponto com geoquímica de $\mathrm{P}$ anômalo, contudo, através do processamento utilizando o método de regressões múltiplas, onde foram integradas informação de geofísica e geoquímica, foram mapeadas feições anômalas em U, F e P, estas cortadas pelo perfil levantado. A princípio o perfil seria uma linha retilínea EW, porém devido a problemas com superfíciário e a não autorização da abertura de picadas, a linha foi modificada para a atual (perfil vinho na Figura 2).

A geologia ao longo deste perfil varia um pouco, passando de solo silto-argiloso, por uma zona de falha com xisto e seixos de quartzo, e siltito. Existe ainda, mapeado pela Itafós na área, afloramentos de fosforito, o qual aparentemente é interseptado pelo perfil em duas ocasiões.
A Figura 3 apresenta os dados pós-processados dos radioelementos $\mathrm{U}$, Th e $\mathrm{K}$; a contagem total (cps), e; as razões $\mathrm{U} / \mathrm{Th}$ e $\mathrm{U} / \mathrm{K}$.

O perfil do radioelemento $\mathrm{K}$ (Figura 4a), apresenta valores médios em torno de 1,5 a 2 porcento, abaixo da média da crosta $(2,5 \%)$. Contudo, pode-se observar em torno da coordenada leste 305500 um pico de concentração do elemento que chega a quase $4 \%$. Nos últimos 300 metros do perfil nota-se também uma queda significativa nos valores de $\mathrm{K}$.

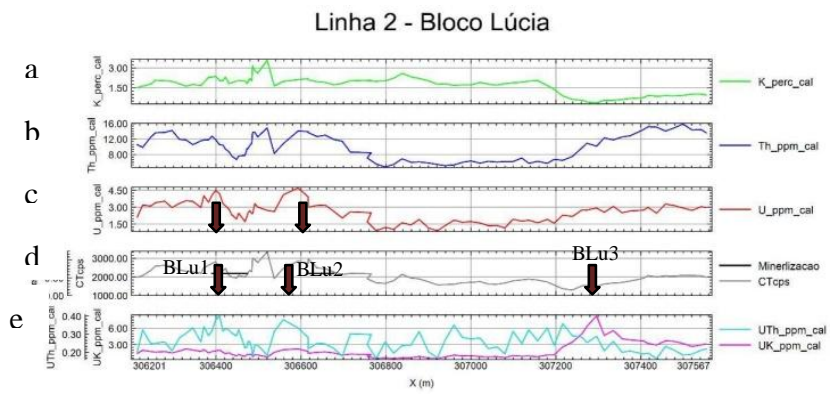

Figura 4 - Perfis dos valores dos radioelementos $K(a)$, Th (b), $U$ (c) e a contagem total (d) coletados no campo, e as razões UTh e UK (e) para o Bloco Lúcia. As setas marrons indicam regiões anômalas.

A variação de valores de tório é significativa ao longo de todo o perfil b (Figura 4), entre 4 e $16 \mathrm{ppm}$. No primeiro $1 / 3$ do perfil os valores são mais expressivos, destacando-se um pico bem marcado com concentração em torno de $15 \mathrm{ppm}$ do elemento, acima da média da crosta (8-12 ppm). Depois deste trecho, ocorre uma queda na concentração do Th ao longo de quase 400 metros de extensão, sendo que os valores encontrados aqui apresentam uma média de $5 \mathrm{ppm}$. Na parte final do perfil os teores voltam a subir consideravelmente, atingindo novamente valores de até $16 \mathrm{ppm}$.

O perfil do urânio (Figura 4c) apresenta um padrão parecido com o perfil do tório (Figura $4 \mathrm{~b}$ ) onde o valor médio do primeiro trecho da linha é mais elevado, sofrendo uma queda na porção central e um ligeiro aumento na parte final da linha. Na parte incial ainda, destacam-se dois pico mais evidentes com maiores concentrações de urânio, atingindo valores relativamente elevados de até $4,5 \mathrm{ppm}$.

O perfil da contagem total mostra (Figura 4d) um comportamento mais regular, com variação menos significativas, porém não menos importantes. A primeira metade do perfil $4 \mathrm{~d}$ apresenta pelo menos 3 picos importantes, sendo o pico central o mais evidente, e os laterais (indicados pelas setas) com importância relevante, se levado em consideração a presença dos corpos mineralizados mapeados pela Itafós assinalados no perfil. A segunda metade apresenta um comportamento mais constante, não apresentando feições importantes.

O perfil da razão UTh (Figura 4e) apresenta um comportamento regular com um pico bastante evidente no último quarto da linha, indicado pela seta BLu3 (Figura 4). Em compensação o perfil da razão UK (Figura 3e) apresenta um padrão irregular, com vários altos e baixos 
ao longo dele, pode-se observar picos marcantes neste perfil, identificados pelas setas BLu1 e BLu2 (Figura 4) marcando bem as regiões mineralizadas. Estes pontos são indicados como pontos de cheque de campo.

Analisando especialmente os dois trechos onde foram posicionadas as mineralizações mapeadas na área e os perfis dos radioelementos, pode-se verificar que existe um deslocamento de alguns metros para sul entre a mineralização e os picos de urânio (Figura 4c) com mais de 3 ppm, e que nestas mesmas regiões o perfil da razão UTh (Figura 4e) também apresenta valores relativamente elevados de $U$ e Th. O pico evidenciado no perfil da razão UK (Figura 4e), e denomeado BLu3 (Figura 4), merce uma investigação mais detalhada. Partindo do princípio e análise de outros perfis como os blocos Lúcia e Coité, nos quais os corpos mineralizados apresentam respostas das razões UTh e UK com valores elevados.

\section{Perfil 3}

Localizado no Bloco Cabeçudo, o perfil 3 possui 3.709 m de extensão com direção E-W, cortando duas litologias distintas pelo mapa do SIG de Goiás (Moreira et al., 2008), porém pelo mapeamento da Itafós, esta região apresenta apenas siltito. Este perfil atravessa anomalias de U e F bastante evidentes nos mapas destas unidades, e não possui nenhuma anomalia de fósforo relacionada (perfil verde na Figura 2). O perfil está localizado quase exclusivamente em área de pastagem, cruzando um brejo no final da linha, a leste.

A geologia ao longo deste perfil apresenta-se bastante monótona, com litologia predominantemente siltosa, ocorrendo apenas pequens variações composicionais e de coloração. A topografia não varia muito ao longo do perfil, e a vegetação vai de pasto, a áreas desmatadas, e floresta. Como indicado pela seta azul na Figura 5a, nesta região existe uma zona de brejo, ou seja, com presença de água.

A Figura 5 apresenta os dados pós-processados dos radioelementos $\mathrm{U}$, Th e $\mathrm{K}$; A contagem total (cps), e; as razões $\mathrm{U} / \mathrm{Th}$ e $\mathrm{U} / \mathrm{K}$.

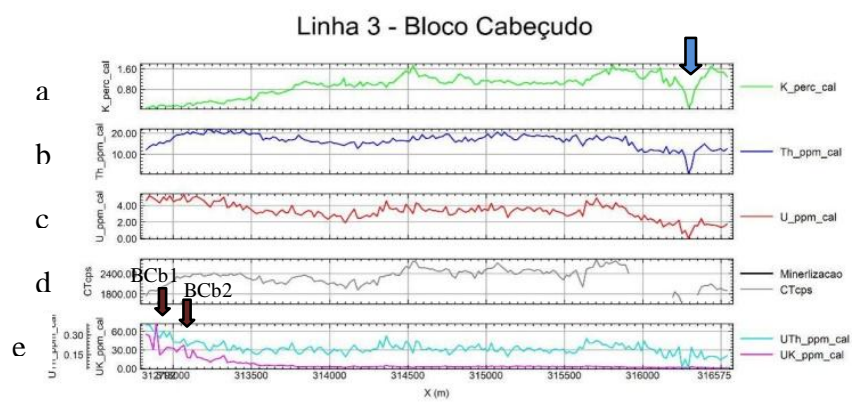

Figura 5 - Perfis dos valores dos radioelementos $\mathrm{K}(\mathrm{a})$, Th (b), $\mathrm{U}$ (c) e a contagem total (d) coletados no campo, e as razões UTh e UK (e) para o Bloco Cabeçudo. A seta azul indica uma região de brejo, e as setas marrons feições anômalas.

$\mathrm{O}$ perfil do $\mathrm{K}$ (Figura $5 \mathrm{a}$ ) apresenta nesta linha um comportamento com baixa concentração do elemento no início, elevando este teor para em torno de 0,8\%, e com alguns picos chegando a $1,6 \%$, como ocorre no centro e no final do perfil, todos os valores estão abaixo da concentração média deste elemento na crosta (2,5\%). Na região indicada pela seta azul os teores decaem abruptamente, representando bem a presença de água.

Os valores de Th não apresentam variações significativas ao longo de todo o perfil $5 b$ (Figura 5 ), a excessão da região mapeada com a presença de uma área de brejo (indicada pela seta azul), onde os valores decaem de 10 ppm para quase $0 \mathrm{ppm}$. Os teores médios te Th ao longo do perfil estão em torno de 15 ppm, portanto acima dos valores médios deste elemento na crosta (8-12 ppm).

Assim como acontece no perfil $5 b$, o perfil do urânio (Figura 5c) não apresenta variações significativas em seus teores, a excessão dos últimos 500 metros, onde existe uma região de brejo mapeado e os valores tendem a 0 ppm. Os valores de urânio ao longo do perfil apresentam um valor médio acima de 3 ppm, o que pode ser considerado elevado para o elemento se considerado que a média do elemento na crosta terrestre é de 2 ppm.

A contagem total apresenta um perfil (Figura 5d) com variações mais evidentes, como no início e final do perfil onde os valores de concentração de radioelementos são mais baixos e, na porção central onde os valores aumentam, porém com nenhum pico mais evidente.

O perfil da razão UTh (Figura 5e) apresenta um comportamento bastante regular apresentando apenas um baixo na região do brejo, e um alto no início do perfil, mas nada muito significativo. Com relação ao perfil da razão UK (Figura 5e), este apresenta uma porção anômala no início da linha, com valores mais elevados e um pico, indicado pela seta marrom BCb1 (Figura 5) bem marcado. Nesta região pode-se observar um enriquecimento em urânio em relação ao potássio.

No início do perfil existe uma faixa de aproximadamente 700 metros onde o U (Figura 5c) apresenta teores com cerca de 4 ppm, e onde os teores de K são quase nulos. Apesar dos corpos mineralizados conhecidos na região terem extensões menores que 100 metros, este trecho assinalado com a seta BCb2 (Figura 5) apresenta um padrão interessante, se comparado aos padrões que ocorrem onde existe mineralização conhecida, merecendo uma melhor investigação. Estes pontos assinalados nos perfis $5 e$ (Figura 5 ) das razões são indicados como pontos de cheque de campo.

Como se pode observar no perfil 5d (Figura 5), existem trechos de linha com falta de informação, estes correspondem aos períodos onde não foi possível a anotação analógica dos dados devido a um problema momentâneo no visor do equipamento. Cabe ressaltar que mesmo sem anotação dos valores, foi realizado o armazenamento digital dos dados, o que não comprometeu o levantamento.

\section{Perfil 4}

Localizado no Bloco Avião, o perfil 4 encontra-se logo atrás da Mineração Itafós, com $850 \mathrm{~m}$ de extensão. O perfil, primeiramente traçado com direção $\mathrm{E}-\mathrm{W}$, foi modificado devido a problema com superficiário, sendo então executado ao longo de estradas secundárias existentes na região. O levantamento realizado corta as 
anomalias de fluor e fósforo mapeados para a região, porém sem nenhuma anomalia de urânio. O relevo na região é bastante acidentado, porém ao longo de quase todo o perfil existia rocha aflorante. A litologia na área é domindada por siltito. A área se encontra próximo a um ponto de amostragem geoquímica com valor do elemento $\mathrm{P}$ acima de 600 ppm (perfil azul na Figura 2).

O perfil aqui levantado corta essencialmente solo siltoso, com fragmentos de siltito e afloramento de siltito, localmente. O levantamento foi realizado sobre a estrada secundária que corta a área. Existe na região um corpo de fosforito mapeado pela Itafós (Figura 6d).

A Figura 6 apresenta os dados pós-processados dos radioelementos $\mathrm{U}$, Th e $\mathrm{K}$; $\mathrm{A}$ contagem total (cps), e; as razões $\mathrm{U} / \mathrm{Th}$ e $\mathrm{U} / \mathrm{K}$.

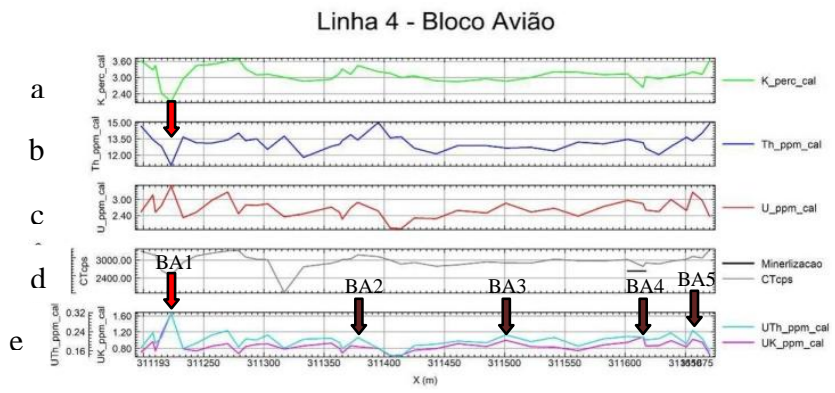

Figura 6 - Perfis dos valores dos radioelementos $K(q)$, Th (r), U (s) e a contagem total ( $\mathrm{t}$ ) coletados no campo, e as razões UTh e UK (v) para o Bloco Avião. As setas deste perfil indicam feições anômalas, sendo as em vermelho com prioridade 1 e as marrons com prioridade 2 .

O K apresenta uma depleção bastante marcada logo no início do perfil 6 a (Figura 6), porém no restante da linha mostra valores que variam em torno de $3 \%$, localmente atingindo 3,6 \%. Na região onde foi marcada a existência de mineralização (esta mapeada próximo da linha), ocorre uma ligeira queda na concentração de potássio. Nos últimos metros da linha o teor do radioelemento sofre outro aumento.

O tório apresenta uma queda significativa no início do perfil 5b (Figura 6), onde também diminuiu a concentração de $\mathrm{K}$, porém aumentando os teores para uma média de $13 \mathrm{ppm}$. Próximo da coordenada leste 311400 ocorre um pico do elemento, que atinge o patamar de 15 ppm. A exemplo do que ocorre com o potássio, nos últimos metros da linha o tório tem um aumento na concentração.

O perfil do $U$ (Figura $6 \mathrm{c}$ ) mostra um comportamento irregular, com um pico bastante acentuado no início da linha (seta vermelha). Possui ainda dois picos menores tanto do lado direito, como do lado esquerdo deste pico principal. Estes três altos no perfil de U possuem teores maiores que $3 \mathrm{ppm}$. Seguindo em direção ao final da linha ocorrem variações entre 1,6 e 3 ppm do elemento, e no final da mesma, um novo pico do radioelemento com teor acima de 3 ppm. Na região da mineralização ocorre um ligeiro aumento nas concentrações do elemento, elevando os teores para 3 ppm.

O perfil da contagem total (Figura 6d) apresenta um comportamento mais constante, com duas grandes depleções, uma no início do perfil onde ocorre o pico do urânio, e a outra próxima da coordenada leste 311320 . Pode-se observar ainda que na região onde foi assinalada a mineralização, ocorre uma ligeira queda nas concentrações dos radioelementos.

No perfil 6e das razões UK e UTh (Figura 6), pode-se observar um pico bem marcado no início da linha, este indicado pela seta vermelha BA1 (Figura 6) e outros picos menos evidentes ao logo de toda a linha assinalados com as setas marrons denominadas BA2, BA3, BA4 e BA5 (Figura 6).

Apesar da litologia mapeada ao longo de todo o perfil ser constante, siltito, pode-se verificar variações na composição do mesmo através da indicação dos perfis dos 3 radioelementos ( $\mathrm{K}$, Th e $\mathrm{U})$. Como analisado individualmente, na região onde foi traçada a localização de uma ocorrência de minério próximo da linha levantada, os valores de $\mathrm{K}$ sofrem uma ligeira queda, enquanto os valores de Th e $U$ apresentam uma pequena elevação, o que também é observado nos perfis das razões.

As setas no perfil das razões (Figura 6e) indicam locais de cheque de campo, sendo que a seta vermelha (BA1, Figura 6) inidica prioridade um, e as setas marrons prioridade secundária. Estes picos indicam um enriquecimento de urânio em relação aos radioelementos Th e K. Estes pontos são indicados como pontos de cheque de campo.

\section{Perfil 5}

Localizado no Bloco Coité, o perfil 5 encontra-se no estado do Tocantins, área onde existe uma cava de extração de fosfato pela Itafós, porém sem nenhuma informação de geofísica aérea. Este perfil possui $580 \mathrm{~m}$ de comprimento com direção E-W, ao longo do qual foram executadas 28 leituras. O levantamento cruza um corpo de fosforito mapeado. Este perfil foi escolhido por já ter amostragem de solo para geoquímica, além de levantamentos geofísicos com GPR e Imageamento elétrico bidimensional (perfil roxo na Figura 2).

A litologia que predomina a longo deste perfil é o siltito, sendo que existe um corpo fosforítico mapeado (Figura 7d) pela Itafós. Foram encontrados localmente fragmentos de silexito. A posição indicada pela seta azul (Figura 6a) marca a existência de um córrego que corta o perfil. A área possui o relevo um pouco acidentado e no início da linha onde a vegetação é pasto, passando para uma vegetação de maior porte próximo ao córrego.

A Figura 7 apresenta os dados pós-processados dos radioelementos $\mathrm{U}$, Th e K; A contagem total (cps), e; as razões U/Th e U/K.

O perfil do potássio (Figura 7a) apresenta um comportamento marcado por um alto no início da linha e uma queda significativa dos valores da metade da linha até o final. Os valores variam de aproximadamente $4 \%$ nas regiões mais altas, atingindo em torno de $0 \%$ na região mais baixa, região esta que apresenta um corpo de fosforito mapeado pela Itafós. Na porção indicada pela seta azul, ocorre uma pequena queda no valor do elemento, marcando assim a existência de um córrego. 


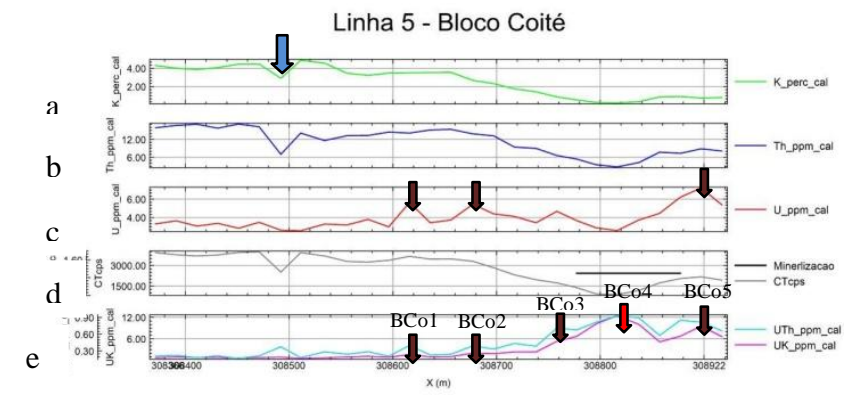

Figura 7 - Perfis dos valores dos radioelementos $\mathrm{K}(\mathrm{a})$, Th (b), $\mathrm{U}$ (c) e a contagem total (d) coletados no campo, e as razões UTh e UK (e) para o Bloco Coité. A seta azul indica a presença de um córrego na área, e as outras setas regiões consideradas anômalas nos perfis. A seta vermelha indica prioridade 1 de investigação e, as marrons, prioridade 2 .

O Th (Figura 7b) apresenta um comportamento bastante semelhante ao do potássio $(\mathrm{X})$, com os maiores valores (18 ppm) entre o início e a metade da linha, tendo uma queda significativa nos teores da metade até o final, onde atinge no seu ponto mais baixo valores em torno de 4 ppm, tendo um ligeiro aumento no final da linha.

O U (Figura 7c) apresenta valores elevados ao longo de toda a linha, variando entre 2 e 7 ppm. Ocorre uma variação entre 2 e 4 ppm do início até quase a medate da linha, aparecendo dois picos de quase 6 ppm no centro da linha, assinalados com as setas marrons. Existe um pico um pouco menos evidente próximo da coordenada leste 308750 . Sobre a mineralização mapeada na região, ocorre uma ligeira queda nos valores de $U$, porém estes continuam elevados, acima de 3 ppm. No final da linha, assinalado pela seta marrom, ocorre um pico que atinge aproximadamente $7 \mathrm{ppm}$ de $\mathrm{U}$.

A contagem total (Figura 7d) apresenta o mesmo comportamento dos elementos $\mathrm{K}$ e $\mathrm{Th}$, com valores mais elevados no início da linha, uma ligeira queda na região onde existe o córrego, e uma queda dos valores na região onde foi mapeado o corpo mineralizado.

Os perfis das razões UK e UTh (Figura 7e) apresentam comportamentos semelhantes entre si, e com o perfil do urânio. Valores baixos no início do perfil e um aumento significativo no último terço da linha, ou seja, uma tendência de crescimento de oeste para leste. Ao longo destes perfis foram assinalados com setas 5 picos de enriquecimento de $\mathrm{U}$ em relação ao $\mathrm{Th}$ e ao $\mathrm{K}$, sendo os dois primeiros, BCo1 e BCo2 (Figura 7) com uma amplitude menor, e os três últimos, BCo3, BCo4 e BCo5 (Figura 7) com amplitude maiore. É possível observar que a maior amplitude de enriquecimento de $U$ relativo ocorre onde o fosforito foi mapeado e está assinalado no perfil, o que caracteriza que as regiões mineralizadas apresentariam baixos valores de $\mathrm{K}$ e Th em relação ao U. Estes pontos são indicados como pontos de cheque de campo.

\section{Discussão e Conclusões}

No perfil 5, correspondente ao Bloco Coité, é relevante ressaltar a marcante tendência de crescimento na razão UK (Figura 7e) no sentido de oeste para leste. Observese que os maiores valores da razão coincidem com a área mineralizada, provando assim a eficiência do método gamaespectrometrico para o mapeamento de mineralização.

As áreas marcadas nos perfis 6dw (Figura 7), apesar de não apresentarem valores de U muito acima da média da crosta, apresentam valores relativos elevados (valores médios em torno de 3 a 4 ppm). Alguns pontos apresentam picos de $U$ com depleções de $\mathrm{K}$ e Th, indicações importantes de que há uma correlação inversa entre estes elementos, o que mostrou serem as razões os melhores produtos para mapear o fosforito.

Como se pode observar nos perfis onde há informações de mineralização (Figura 4d; Figura 6d; Figura 7d), ocorre um pequeno deslocamento entre a faixa mineralizada e os picos de urânio. Estas informações têm bases de posicionamento diversas e podem conter distorções em função da aquisição por diferentes GPS, os quais apresentam margem de erro de variada.

Após a análise dos cinco perfis de gamaespectrometria terrestre, podemos afirmar que:

1. Os perfis da razão UTh e UK são os melhores mapeadores de mineralização de fosforito. Visto que todas as mineralizações conhecidas nos perfis apresentam valores elevados com picos bem marcados nestes dados;

2. Foram selecionados dezessete locais para investigação de anomalias de radioelementos. Destas oito com prioridade um e nove com prioridade dois. Sugere-se que sejam realizadas amostragem com trado nestas regiões para análise.

\section{Agradecimentos}

Os autores agradecem a UnB por toda a infraestrutura e equipamentos cedidos e, a Itafós Mineração Ltda pelo apoio na etapa de campo, pelas informações disponibilizadas e pela permissão para publicação destes dados.

\section{Referências}

Dardenne, M. A. 1978. Síntese sobre a estratigrafia do Grupo Bambuí no Brasil Central. In. SBG, Congresso Brasileiro de Geologia, 30, Recife, Anais, 2: 597-610.

Exploranium - A division of SAIC Canada, 2007. GR-320. Portable Gamma Ray Spectrometer. Users' Manual. Revision 3.5.

Ferreira, C. J., Moreira-Nordemann, L. M. e Nordemann, D. J. R. 1992. A radioatividade natural da região de Irecê, BA. Revista Brasileira de Geociênias. 22 (2) : 167-174.

IAEA - International Atomic Energy Agency, 2003. Guideline for radioelement mapping using gamma ray spectrometry data. Vienna, Austria.

Moreira, M. L. O., Moreton, L. C., Araújo, V. A., Lacerda, J. V. e Costa, H. F. 2008. Geologia do Estado de Goiás e Distrito Federal. Escala 1:500.000. Goiânia: CPRM/SIC FUNMINERAL. 141p. 